\title{
On tropical cyclone frequency and the warm pool area
}

\author{
R. E. Benestad \\ Norwegian Meteorological Institute, P.O. Box 43, 0313, Oslo, Norway
}

Received: 23 April 2008 - Revised: 20 April 2009 - Accepted: 20 April 2009 - Published: 30 April 2009

\begin{abstract}
The proposition that the rate of tropical cyclogenesis increases with the size of the "warm pool" is tested by comparing the seasonal variation of the warm pool area with the seasonality of the number of tropical cyclones. An analysis based on empirical data from the Northern Hemisphere is presented, where the warm pool associated with tropical cyclone activity is defined as the area, $A$, enclosed by the $26.5^{\circ} \mathrm{C} \mathrm{SST}$ isotherm. Similar analysis was applied to the temperature weighted area $A_{T}$ with similar results.

An intriguing non-linear relationship of high statistical significance was found between the temperature weighted area in the North Atlantic and the North-West Pacific on the one hand and the number of cyclones, $N$, in the same ocean basin on the other, but this pattern was not found over the North Indian Ocean. A simple statistical model was developed, based on the historical relationship between $N$ and $A$. The simple model was then validated against independent inter-annual variations in the seasonal cyclone counts in the North Atlantic, but the correlation was not statistically significant in the North-West Pacific. No correlation, however, was found between $N$ and $A$ in the North Indian Ocean.

A non-linear relationship between the cyclone number and temperature weighted area may in some ocean basins explain both why there has not been any linear trend in the number of cyclones over time as well as the recent upturn in the number of Atlantic hurricanes. The results also suggest that the notion of the number of tropical cyclones being insensitive to the area $A$ is a misconception.
\end{abstract}

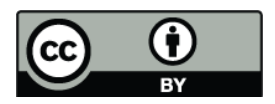

Correspondence to: R. E. Benestad (rasmus.benestad@met.no)

\section{Introduction}

High numbers of Tropical cyclones (TCs) in the Atlantic and Caribbean during 2004 (15 named TCs) and 2005 (27 named $\mathrm{TCs}^{1}$ ) have recently spurred speculations of whether TCs can be affected by a global warming (Klotzbach and Gray, 2008; Trenberth, 2005; Scharroo et al., 2006; Sun et al., 2006; Michaels et al., 2006; Knutson and Tuleya, 2005; Pearce, 2005a; Smith, 2005; Trenberth et al., 2007). Furthermore, in 2006 there were 9 named Atlantic TCs, despite the presence of an El Niño and possible cooling effects from Saharan dust (Lau and Kim, 2007), and in 2007 there were 15 named Atlantic tropical cyclones.

Details of the physical conditions and processes associated with TC formation and their intensity are poorly known (Holland, 1997). It is nevertheless well-known that the formation of tropical cyclones requires sea surface temperatures (SST) greater than $26-27^{\circ} \mathrm{C}$ (Holland, 1997; Gray, 1968), whereas strong vertical wind shear in the troposphere provides unfavourable TC conditions (Goldenberg et al., 2001; Pearce, 2005b; Henderson-Sellers et al., 1998; Holland, 1997). Furthermore, the heat conversion associated with evaporation near the surface and condensation associated with cloud formation aloft plays a central role in the TC energetics.

A remote sensing study of Hurricane Katarina-2005 suggests that the rapid increase in the intensification of the hurricane was more likely due to oceanic dynamic topography, representing the upper ocean heat content, rather than SST (Scharroo et al., 2005, 2006). Stirring of the upper ocean layers by the high winds associated with TCs brings cooler subsurface water up to the surface, and merely high SST is not a sufficient condition for TC formation. But a deep

\footnotetext{
${ }^{1}$ Three of which were category-5, four landfalls caused extensive damages, and Wilma reached the highest intensity on record in the Atlantic basin: http://en.wikipedia.org/wiki/Hurricane_Wilma.
} 
thermocline is required as well to maintain high SSTs during the mixing or Ekman pumping caused by TCs. As these aspects are not mutually independent, high SSTs are often associated with a thick upper layer of warm water.

TCs are also associated with a warm core aloft that have both dynamical and thermodynamical implications for the cyclone character (Holland, 1997). A change in the vertical stability is likely to have a pronounced effect on the TC statistics, while high temperatures near the surface and increased specific humidity implies increased energy input for the TC process (Holland, 1997). If a Carnot heat engine perspective can be used as an analogy for the work done by a $\mathrm{TC}$, then the efficiency $\left(1-\mathrm{T}_{C} / T_{H}\right)$ of an "engine cycle" is lower for smaller temperature differences between the warm $\left(T_{W}\right)$ and cold $\left(T_{C}\right)$ states.

There has been a number of studies discussing $N$ and longterm trends in the TC frequency, and there have been reports of increased activity (e.g. number of TCs) in the period 1995-2000 compared to 1971-1994, due to increases in the North Atlantic SST and a decrease in wind shear.

Lau et al. (2008) reported positive significant trends in heavy rain over the North-West Pacific and the North Atlantic during the 1979-2005 period. They argued that TCs may have fed increasingly more to rainfall extremes in the latter, and suggested that an expansion of the warm pool area may explain slightly more than $50 \%$ of the change in observed trend in total TC rainfall. For the North-West Pacific, however, there was no such unambiguous trend in TCs.

Goldenberg et al. (2001) posed the question whether the increased activity was due to the long-term global warming or just a result of natural variability, but concluded that the latter was the most likely explanation. They argued that the recent high North Atlantic SST and reduced vertical shear will persist for some years to come, and suggested that the high activity is likely for subsequent $10-40$ years.

Wu et al. (2006) argued that there has been no increase in Western North Pacific category 4-5 typhoon activity, and that the best track data from the Hong Kong Observatory shows a decrease in the proportion of category 4-5 typhoons from $18 \%$ to $8 \%$ between the two periods of $1977-1989$ and 1990 2004.

Furthermore, Klotzbach (2006) found no evidence for any significant trend in the global accumulated cyclone energy (ACE) or in category 4-5 hurricanes.

Other studies, based on past empirical evidence, have on the other hand suggested that the potential destructive energy in TCs has increased since 1970 (Emanuel, 2005) or that the number of intense cyclones has risen over the time period (Hoyos et al., 2006; Webster et al., 2005).

Looking at the statistics of land-falling TCs, Landsea (2007) argued that early TC count was underestimated due to less complete observing systems in the past, whereas Mann et al. (2007) maintained that there has been a trend in the number of TCs in the Atlantic, even after a bias is taken into account. On the other hand, Holland (2007) argued that the ratio of land-falling cyclones to the total number is not constant and hence that Landsea et al.'s adjustment is unjustified. Klotzbach and Gray (2008) carried out an analysis of North Atlantic TCs, and concluded that both the total and number of land-falling TCs vary with the Atlantic multi-decadal oscillation (AMO).

Thus, different data sets and studies provide different accounts on the long-term trends in the cyclone activity, and any clear and systematic change in the global total number of TC has not yet been detected (Trenberth et al., 2007). Moreover, a lack of trend may seem contrary to expectations, given a general warming trend.

Global climate models (GCMs) provide an important tool for making future climate scenarios, but these do not yet have a sufficient spatial resolution or a representation of the physical processes within the individual storm systems to give accurate results (Yoshimura et al., 2006; Chauvin et al., 2006; Henderson-Sellers et al., 1998; Jung et al., 2006; Vitard et al., 2007; Randall et al., 2007). Most of the GCMs with spatial resolution of $50-100 \mathrm{~km}$ or lower cannot accurately simulate the observed TC intensity (Meehls et al., 2007). Nevertheless, GCMs may give a reasonable description of the geographical tropical cyclone statistics (Randall et al., 2007). Yet, the IFS from the European Centre for Medium Weather Forecasts (ECMWF), a higher-resolution GCM, exhibits some biases with respect to the TC climatology in terms of number and the phase of the seasonal cycle (Vitard et al., 2007), and such biases are also found in other GCMs (Yoshimura et al., 2006).

Several model studies have investigated whether TCs will become more frequent or more intense under a global warming, and some model results indicate an increase in intensity and near-storm precipitation rates with $\mathrm{CO}_{2}$-induced warming (Knutson and Tuleya, 2004). But moderately highresolution model-based studies by Yoshimura et al. (2006), Bengtsson et al. (2006), and Chauvin et al. (2006) suggest a decreasing number of TCs globally, although the intensity and the number of intense TCs may increase (Meehls et al., 2007). One explanation for a reduction in the total number of TCs is that stronger warming aloft in the tropics results in enhanced stability of the tropical troposphere (Meehls et al., 2007).

Henderson-Sellers et al. (1998) argued that there is a widespread misconception ${ }^{2}$ that the tropical cyclogenesis increases with the area enclosed by the $26^{\circ} \mathrm{C}$ SST isotherm and based their statement on an application of a thermodynamic technique (Holland, 1997). But the thermodynamic technique cited by Henderson-Sellers et al. (1998) is relevant for the intensity of TCs, not their frequency. The warm

\footnotetext{
${ }^{2}$ Quote: "For example, a widespread misconception is that were the area enclosed by the $26^{\circ} \mathrm{C} \mathrm{SST}$ isotherm to increase, so too would the area experiencing tropical cyclogenesis... In particular, there is no reason to believe that the region of cyclogenesis will expand with the $26^{\circ} \mathrm{C}$ isotherm."
} 
area $A$, the vertical temperature, and humidity profiles may on the contrary have different effects on TCs intensity and frequency.

Hence, the question of whether there is a systematic relationship between the area of high SST and number of TCs has not yet been settled. A search with scholar.google.com and ISI web of Science [v3.0 $]^{3}$ found no publications where relationship between $A$ and TC frequency had been studied, except for the unsupported claim about warm area and frequency in Henderson-Sellers et al. (1998).

The statement about the relationship between the warm area and cyclogenesis is examined here through a different data analysis approach, as Henderson-Sellers et al. (1998) do not provide convincing evidence for why the cyclogenesis should not be sensitive to warm pool area.

Here only the frequency of tropical cyclones in the Northern Hemisphere is examined, and the number of cyclones does not necessarily give an adequate indication of the severity of the tropical cyclone activity, as aspects such as trends in individual cyclone life times, intensities (Sun et al., 2006), and spatial size have not been included in this simple analysis. The study is restricted to empirical data and statistical analysis, but it is important that climate models provide similar behaviour.

\section{Data and methods}

\subsection{Data}

The SST was the NOAA extended reconstruction from NOAA $\mathrm{CDC}^{4}$, and the area was computed from the longitude-latitude gridded temperatures $T_{i j}(t)$ (units in ${ }^{\circ} \mathrm{C}$ and $i$ is the index of longitude ${ }^{5} \theta_{i}, j$ is the latitude index $\phi_{j}$, and $t$ is the time) according to:

$$
A(t)=\sum_{i j} w_{j} \mathcal{H}\left(T_{i j}(t)-T_{\text {crit }}\right),
$$

where $w_{j}=\delta \theta \cos \left(\phi_{j}\right) a \times \delta \phi a$ (radius of the earth $a=6.378 \times 10^{3} \mathrm{~km}$ ) is the grid box area in $\mathrm{km}^{2}$, and $\mathcal{H}$ is the Heaviside function:

$\mathcal{H}(x)=\left\{\begin{array}{l}0 \text { for } x<0 \\ 1 \text { for } x \geq 0\end{array}\right.$

Additionally, the analysis repeated for two kinds of temperature weighted area $\left(A_{T}\right.$ and $\left.A_{\tau}\right)$. Subscripts, e.g. $N_{\mathrm{Atl}}$, $N_{\text {Pac }}$, and $N_{\text {Ind }}$, are henceforth used to indicate the region represented by the data/analysis whereas symbols with no subscripts are used for more general discussion.

The North Atlantic warm region $A_{\text {Atl }}$ was estimated as the area with $\mathrm{SST}>26.5^{\circ} \mathrm{C}$ (Holland, 1997; Gray, 1968) over

\footnotetext{
${ }^{3}$ Carried out 6 August 2008, using the search phrase "cyclone area isotherm".

${ }^{4}$ http://lwf.ncdc.noaa.gov/oa/climate/research/sst/sst.html

5 units in radians
}

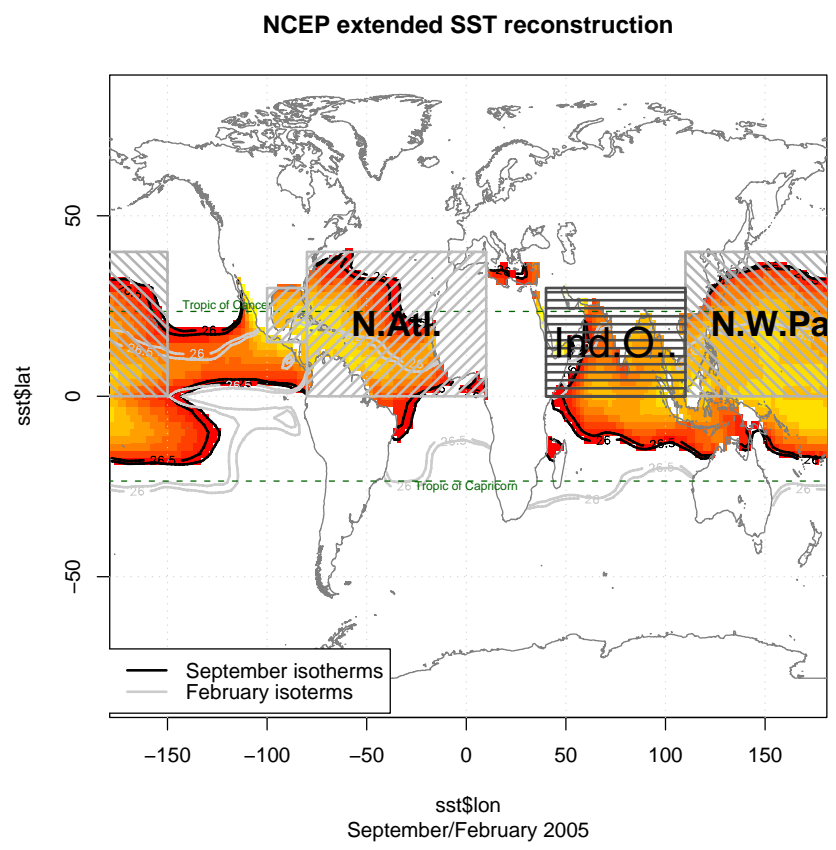

Fig. 1. Map showing the regions (here shown as hatched rectangles) in which $A$ was estimated together with the $26.0^{\circ} \mathrm{C}$ and $26.5^{\circ} \mathrm{C}$ isotherms for February 2005 (grey) and September 2005 (black). The coloured region highlights the areal extent associated with the September $26.0^{\circ} \mathrm{C}$ isotherm, and the green dashed lines mark the Tropics of Cancer and Capricorn.

the region $80^{\circ} \mathrm{W}-10^{\circ} \mathrm{E} / 0^{\circ} \mathrm{N}-40^{\circ} \mathrm{N}$ (the North Atlantic) plus $100^{\circ} \mathrm{W}-80^{\circ} \mathrm{W} / 15^{\circ} \mathrm{N}-30^{\circ} \mathrm{N}$ (Caribbean), the NorthWest Pacific $A_{\mathrm{Pac}}$ over $110^{\circ} \mathrm{E}-150^{\circ} \mathrm{W} / 0^{\circ} \mathrm{N}-40^{\circ} \mathrm{N}$, and the Indian Ocean $A_{\text {Ind }}$ over $40^{\circ} \mathrm{E}-110^{\circ} \mathrm{E} / 0^{\circ} \mathrm{N}-30^{\circ} \mathrm{N}$. Figure 1 shows the isotherms for both September (largest extent in the North Atlantic) and February (smallest extent) as well as the regions in which $A$ was computed (hatched regions).

The exercises were repeated with the critical threshold $T_{\text {crit }}$ set to $26.0^{\circ} \mathrm{C}$ in order to examine the sensitivity to this choice. The value of $A$ is insensitive to the choice of region, as long as the isotherm defining $A$ does not cross the region's boundaries.

The eastern and western border of the North-Western Pacific and the western border of the North Indian Ocean are nevertheless regions where the isotherms do extend beyond the selected regions, and the subjective choice of where to set these was guided by the local geography and the local character of the isotherm variability in order to minimise the sensitivity with respect to $A$.

Thus, the values of $A$ for the North-West Pacific and the North Indian Ocean are associated with a greater degree of uncertainty than the North Atlantic. Slightly different choices of region does affect the details of the statistical fit to some degree if it doesn't enclose all of the warm area, but does not alter the conclusions (e.g. see the results in Benestad, 2006, where a different choice was made: there are some differences in the fit, but the conclusion is the same). 


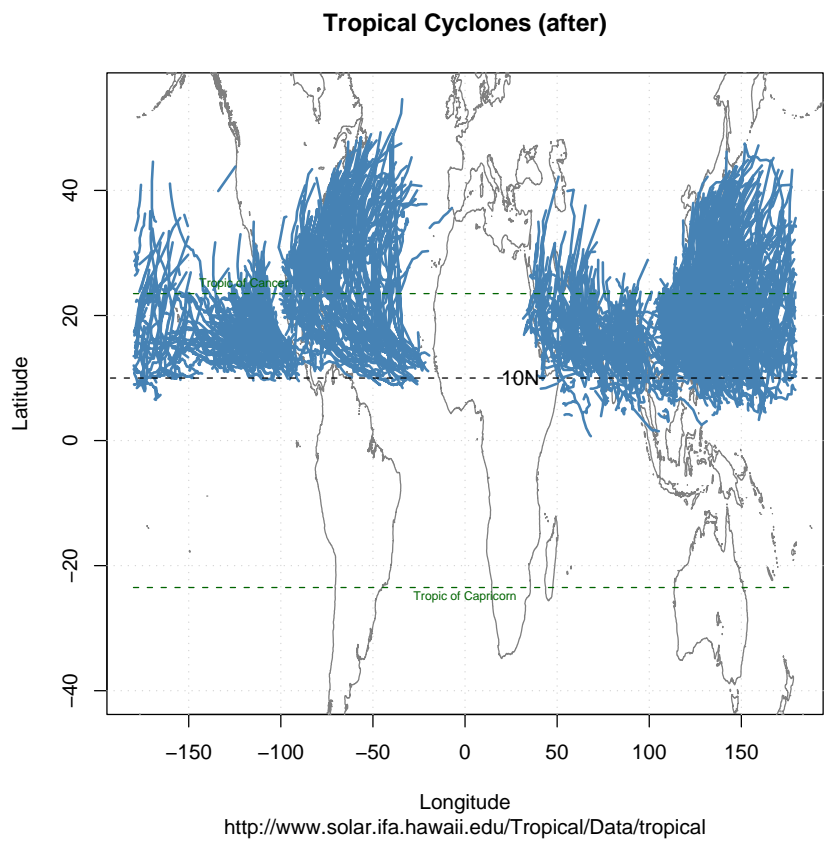

Fig. 2. Map showing the geographical distribution of the Northern Hemisphere tropical cyclones (cyclones in the Southern Hemisphere were not included in the data set and are hence not shown). The black dashed line marks the $10^{\circ} \mathrm{N}$ latitude and the green dashed lines mark the Tropics of Cancer and Capricorn.

This analysis only involves TCs in the Northern Hemisphere. The data on North Atlantic/Caribbean (henceforth referred to as "Atlantic") TCs (1851-2004) was taken from the National Hurricane Center ${ }^{6}$, but the TC data for the North-West Pacific (1950-2003) and the North Indian Ocean (1971-2002) were taken from US Navy best-tracks ${ }^{7}$ (Chu et al., 2002). Figure 2 also shows TC data from Hawaii ${ }^{8}$. Most of the Northern Hemisphere TCs are seen north of $10^{\circ} \mathrm{N}$, due to the fact that Coriolis force diminished towards the equator.

The sorting of TCs into the categories "N.W. Pacific" and "Indian Ocean" involve some uncertainties regarding storms near the $110^{\circ} \mathrm{E}$ longitude (Figure 2).

\subsection{Methods}

The objective of this analysis was to test the hypothesis whether there is a systematic relationship between the number of TCs and the warm area of the region, where SST is greater than $T_{\text {crit }}=26.5^{\circ} \mathrm{C}$ (here represented by the symbol $A$ and henceforth referred to as "the warm area").

\footnotetext{
${ }^{6}$ http://www.aoml.noaa.gov/hrd/hurdat/hurdatTAB.txt

${ }^{7}$ http://metocph.nmci.navy.mil/jtwc/best_tracks/

${ }^{8}$ http://www.solar.ifa.hawaii.edu/Tropical/Data/

${ }^{9}$ This sorting had been done at the data centre.
}

If it can be assumed that (i) there is no systematic change in the atmospheric conditions, (ii) that the TCs are independent of each other, and (iii) TC-formation can be represented by a stochastic process dependent on favourable SST (i.e. Bayesian type statistics), then the probability of observing a TC can be expected to be proportional to $A$, and the probability of a TC occurrence can be expressed as:

$\operatorname{Pr}(\mathrm{TC} \mid A) \propto A$.

The expected number of TCs at any time, $\mu=\mathcal{E}(N)$, is then proportional to the probability, and hence the area $A$. In this case, Eq. (3) represents the hypothesis which is tested here.

Since the TCs may disturb their own environment and influence the large-scale setting, they are strictly not independent. It is possible that they are clustered in time as a result of weak interactions or non-linear behaviour. For instance, the convection associated with TCs may act to maintain low vertical wind shear by equalising upper and lower level horizontal momentum, but TCs also remove heat from the ocean surface through their action of vertical redistribution of heat.

One may nevertheless expect an approximate number of TCs to be proportional to $A$ if the probability of an event is low. The low seasonal number of cyclones and the fact that few TCs coincide in time and space are both consistent with a low probability of occurrence.

In order to reduce the influence of other factors affecting the signal-to-noise ratio, the mean seasonal cycle, rather than the individual years, was used for developing a statistical model for the relationship between the number of TCs and the warm area. If the effect from other influences (e.g. the noise) follows a Gaussian distribution, it will tend to cancel when taking the average over a long interval, as long as these are unrelated to the seasonal cycle or the SST itself. This strategy is inspired by similar approaches used in instrumentation, where phase-locking and "choppers" with predefined frequencies improve the signal-to-noise ratios (e.g. in optics).

Furthermore, the low number of TC-events for each month or season, which in reality reflects a low probability $\operatorname{Pr}(\mathrm{TC} \mid A)$, hampers any attribution analysis. An average over longer interval improves the statistical power, but the question has to be addressed concerning whether the calibration is biased by other factors also exhibiting an annual cycle not related to SST.

\section{Results}

Figure 3a shows a comparison between the annual cycle of (i) the warm area size in the North Atlantic and (ii) the number of TCs. The annual cycle in the TCs, $N$, is represented by a black dashed line whereas the grey curves represent the annual variation in $A$. The seasonal variation in $N_{\text {Atl }}$ and $A_{\text {Atl }}$ both show a clear 12-month annual cycle peaking in September (Fig. 3a). 
It is possible that both respond to the seasonal variation in the angle of solar inclination, however, this would suggest that the response would peak in June for latitudes greater than the Tropic of Cancer ${ }^{10}$ in the Northern Hemisphere, unless there is a similar lag in the SST and TC response.

Due to high heat capacity, the oceans are expected to react more slowly, but the atmosphere tends to respond almost instantaneously. Hence, the same phase lag in the two curves may suggest that the variation in the number of TCs may be influenced by the oceanic state, and only indirectly by the seasonal variation in the solar angle of inclination. In the North Atlantic, the peak in $N_{\text {Atl }}$ and $A_{\text {Atl }}$ is seen in September when the annual variation in the oceanic heat content is at maximum (the same month in the year as the sea-ice extent in the Arctic is at minimum), while in the North-West Pacific (Fig. $3 b), A_{\text {Pac }}$ and $N_{\text {Pac }}$ peak in August ( $A_{\text {Pac }}$ is slightly greater in August than in September).

An interesting observation is that there is not a one-to-one ratio between $N$ and $A$. For the Atlantic region, there is a disproportionally high number $N$ for the month with greatest area $A$. Thus, the hypothesis (Eq. 3) that the number of TCs is proportional to the warm area therefore appears to be inconsistent with these results.

For the North-West Pacific, on the other hand, the annual cycle of $N_{\text {Pac }}$ and $A_{\text {Pac }}$ exhibits more of a linear relationship, however, the peak in TC number is still narrower than that of the warm area.

Over the North Indian Ocean, the seasonal cycle is characterised by a double peak in both temperature-weighted $A_{\text {Ind }}$ and $N_{\text {Ind }}$ (Fig. $3 \mathrm{c}$ ), however, the second peak in $N_{\text {Ind }}$ is more pronounced than the first, whereas the first peak for $A_{\text {Ind }}$ is more prominent than the second. Furthermore, the second annual $N$ peak in the Indian Ocean lags $A$ by one month.

The relationship between the warm surface area and the number of cyclones can be explored further through slightly more sophisticated statistical analysis. The logarithm of the seasonal variation in warm Atlantic surface area $(x=\log (A))$ is compared with the logarithm of the seasonal cycle in monthly mean number of Atlantic TCs, $N_{\text {Atl }}$ $(y=\log (N))$, and a regression was carried out based on the model $\hat{y}_{m}=\alpha x_{m}+\beta$, where $m$ represents the different months in the TC season.

Here a linear relationship was derived between the mean seasonal cycle of $x$ and $y$ taken over the interval 1944-2004. Only the months with $y=\ln (N)>-3$ (May-December) were used to calibrate the model. The relationship between $x$ and $y$ has a predominately linear character (Fig. 4) that implies the expression:

$N_{\text {Atl }} \propto A_{\text {Atl }}^{5.06 \pm 0.25}$.

The linear least-squares regression analysis returned a $p$ value for this relationship of the order $10^{-6}$, adjusted
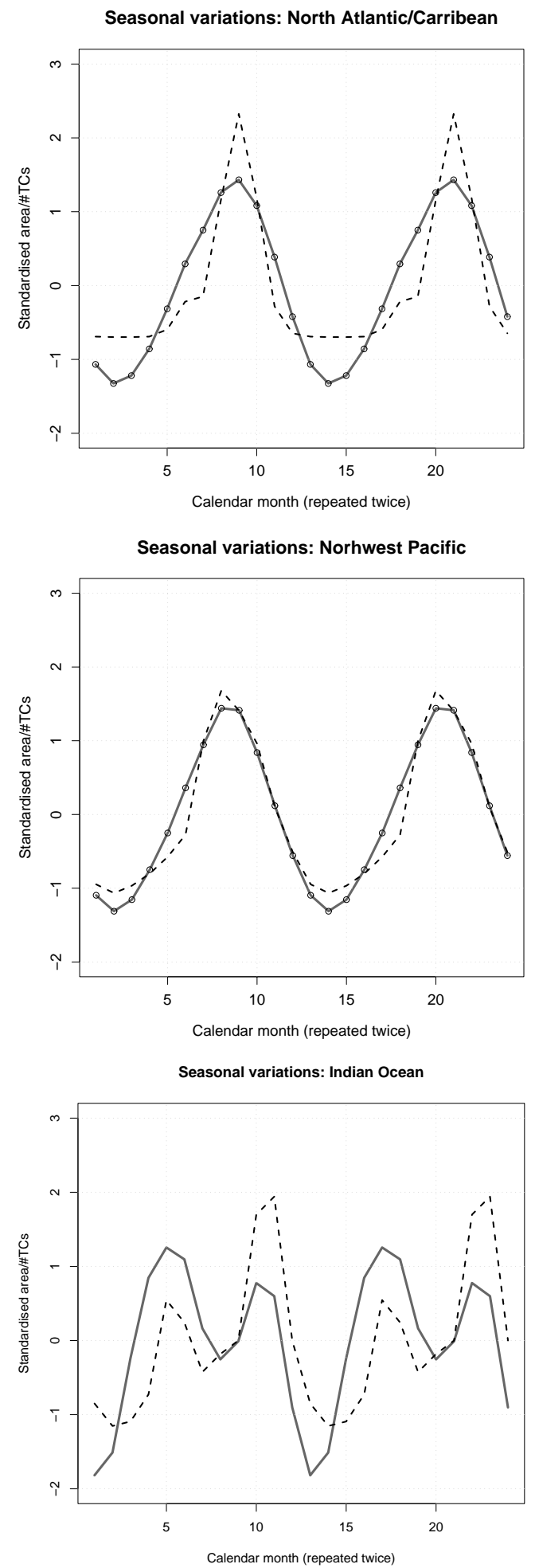

Fig. 3. The annual variation in surface area of SST $>26.5^{\circ} \mathrm{C}$ ( $A$; grey) and the number of TCs $(N$; dashed) for the (a) Atlantic/Caribbean basin, (b) the North-West Pacific, and (c) the Indian Ocean, but for a temperature-weighted area $\left(A_{T}\right)$. All the curves have been standardised.

\footnotetext{
${ }^{10}$ Located at $23.5^{\circ}$ north of the equator.
} 
The Atlantic basin

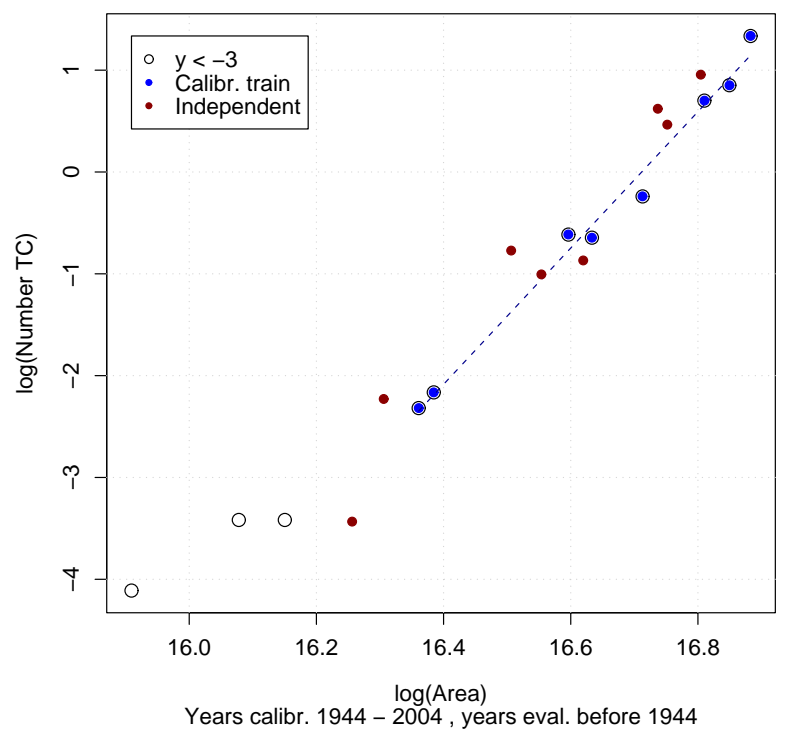

Fig. 4. Scatter-plot of seasonal values $x=\log (A)$ and $y=\log (N)$ for the Atlantic basin. Here $A$ is in units of $\mathrm{km}^{2}$ and $N$ in number/month. Both calibration (dependent) and independent data are shown. Only the months with $\ln (N)>-3$ were used to estimate the best-fit, but these months are also shown as open symbols (independent validation data).

$R^{2}=0.98$, and $F$-statistic of 398 on 1 and 6 degrees of freedom (DF). The same tendency was seen in the independent data over the 1851-1943 period (red symbols in Fig. 4) and the months with very few TCs (open symbols).

The figure shows less than 12 data points for each ocean basin, but each value is a mean estimate of many measurements. The fact that the older independent data shows the same statistical pattern as the calibration data suggests that a deterioration in the data quality, if present, does not have a strong effect on this analysis.

Figures 5-7 show a combined log-log scatter plot for the three ocean basins, and the relationships revealed in this plot point to some intriguing features. The data representing the North-West Pacific indicates similar linear relationship between the $x$ and $y$ as in the North Atlantic/Caribbean, but the slope is slightly weaker: $N_{\mathrm{Pac}} \propto A_{\mathrm{Pac}}^{4.44 \pm 0.37}$ (Adjusted $R$ squared $=0.93, F$-statistic $=146$ on 1 and 10 degrees of freedom, and $p$-value $=2.7 \times 10^{-7}$ ).

The relationship over the North Indian Ocean is poor although the best-fit suggested $N_{\text {Ind }} \propto A_{\text {Ind }}^{3.46 \pm 1.50}$ (Adjusted $R$-squared $=0.35, F$-statistic $=5$ on 1 and $7 \mathrm{DF}$, and $p$ value $=0.05$ ). The double peaks in both $A_{\text {Ind }}$ and $N_{\text {Ind }}$ are somewhat consistent with a close association, but the phase match is not perfect as the second $N_{\text {Ind }}$ peaks one month later than corresponding $A_{T}$ (Fig. 3c), and the magnitudes of the peaks are not consistent. Furthermore, the log-log points in Fig. 4 fall outside the linear fit.

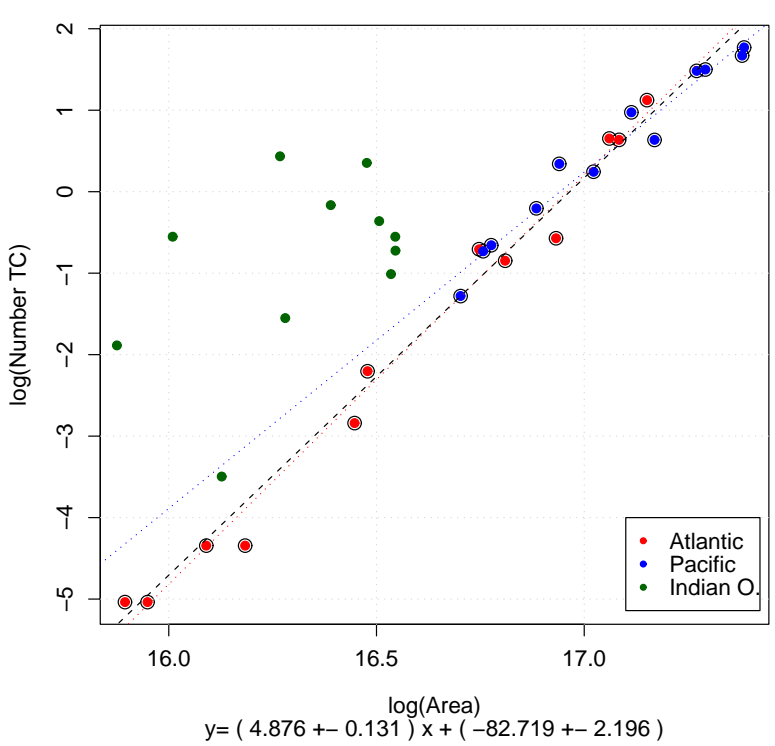

Fig. 5. Scatter-plot of seasonal values $x=\log (A)$ and $y=\log (N)$ for the Atlantic, North-West Pacific and Indian ocean basins. Here $A$ is in units of $\mathrm{km}^{2}$ and $N$ in number/month and the calibration of the fits and the data presented involve all available data. The dashed lines show the best linear-log fits, where the black line represents the combined fit for the Atlatnic and the North-West Pacific.

So far, the possibility that other factors important for TCs also exhibiting an annual cycle cannot not be ruled out, despite the similar phase lag for $N_{\text {Atl }}$ and $A_{\text {Atl }}$ with respect to solar inclination angle.

One way to isolate and assess the importance of the warm sea area with respect to $N$ is then to use the statistical relations derived above to predict year-to-year variations in the seasonal mean number of TCs over an interval representing independent data, and subsequently evaluate against the observations (Fig. 8). This kind of approach was used by Michaels et al. (2006) to assess the association between SST and the total number of annual TCs, however, here the SSTs (in their analysis averaged over $10^{\circ} \mathrm{N}-25^{\circ} \mathrm{N}$ and $15^{\circ} \mathrm{W}-$ $80^{\circ} \mathrm{W}$ ) were substituted with the predicted values using expression 4 (note, the conclusions drawn here contrast with those made by Michaels et al., 2006). One limitation is that Eq. (4) only gives an approximate value, as the relationship is non-linear, and the seasonal mean value may not capture high values associated with high $A$ in individual months.

When the simple model (Eq. 4) was applied to the hurricane-season mean $\overline{A_{\text {Atl }}}$ (June-November) of each year over the 1944-2004 interval (blue curve), a correlation of 0.35 was achieved ( $p$-value $=0.005$, assuming independent and identically distributed data). The results were not sensitive to the particular choice for critical threshold, as when $T_{\text {crit }}=26.0^{\circ} \mathrm{C}$ was used, the correlation was 0.37 ( $p$ value $=0.004)$. 


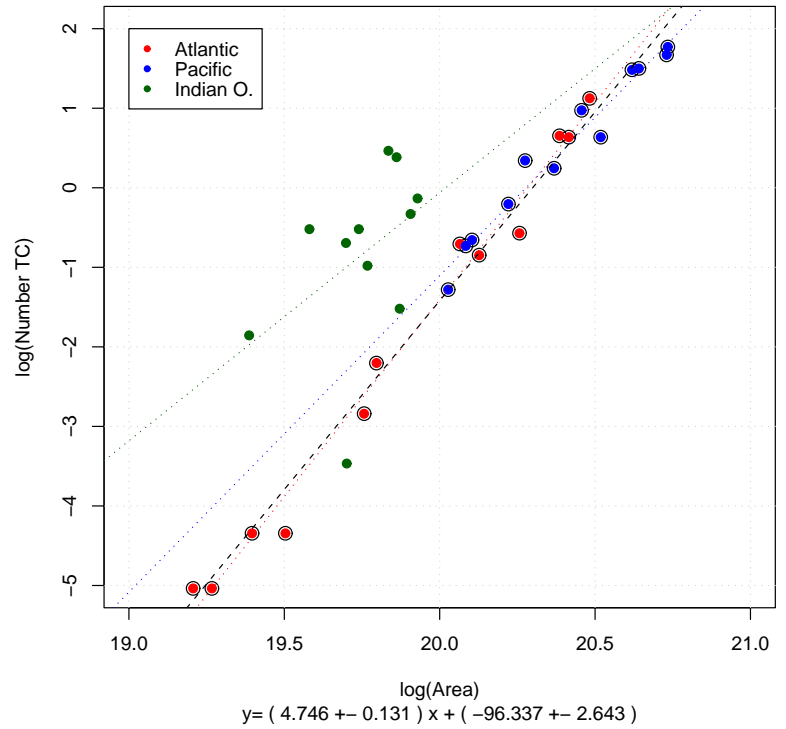

Fig. 6. Scatter-plot of seasonal values $x=\log \left(A_{T}\right)$ and $y=\log (\mathrm{N})$ for the Atlantic, North-West Pacific and Indian ocean basins. Here the temperature-weighted $A_{T}$ is in units of ${ }^{\circ} \mathrm{C} \times \mathrm{km}^{2}$ and $N$ in number/month and the calibration of the fits and the data presented involve all available data. The dashed lines show the best linear-log fits, where the black line represents the combined fit for the Atlatnic and the North-West Pacific.

For the older data (representing 1851-1943; red curve) with presumed lower quality, the analysis with $T_{\text {crit }}=26.5^{\circ} \mathrm{C}$ gave a weaker correlation $(r=0.28)$, but it was still statistically significant at the $1 \%$ level $\left(p\right.$-value $=0.008 ; T_{\text {crit }}=26.0^{\circ} \mathrm{C}$ gave $r=0.29$ with $p$-value $=0.006$ ).

In other words, the empirical expression captures some of the year-to-year variations in the TC numbers over the independent evaluation period. The area of high SST do by no means explain most of the year-to-year variability, and the large differences between the predictions and observations also suggest that other factors are important in determining $N$.

A similar correlation analysis for the North-West Pacific over the independent years 1950-1987 yielded a weak correlation $(r=0.23)$ with a $p$-value of $0.17\left(T_{\text {crit }}=26.0^{\circ} \mathrm{C}\right.$ : $r=0.11$ with a $p$-value $=0.53$ ), and a negative correlation $(r=-0.29)$ for the Indian Ocean over the interval 1971-1992 $(p \text {-values }=0.18)^{11}$. These results are similar to the correlations between regional mean SSTs and the ACE found by Klotzbach (2006), with positive correlations in the North Atlantic and North-West Pacific and negative over other ocean basins.

An assessment of the number of TCs estimated according to Eq. (4), based on the trend in $A_{\mathrm{Atl}}$, also appears to provide a rough description of the long-term trend: When taking a polynomial trend (Benestad, 2003) in $A$ (Fig. 9, left panel)

\footnotetext{
${ }^{11}$ For $T_{\text {crit }}=26.0^{\circ} \mathrm{C}$ the same correlation for the Indian Ocean gave $-0.27(p$-values $=0.20)$
}

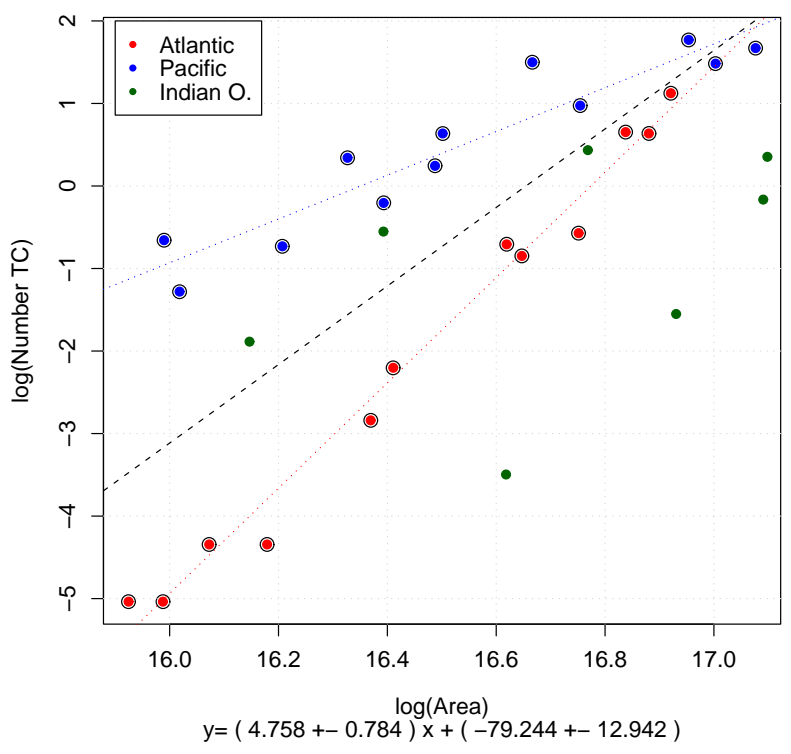

Fig. 7. Scatter-plot of seasonal values $x=\log \left(A_{\tau}\right)$ and $y=\log (\mathrm{N})$ for the Atlantic, North-West Pacific and Indian ocean basins. Here the peak-over-threshold $A_{\tau}$ is in units of ${ }^{\circ} \mathrm{C} \times \mathrm{km}^{2}$ and $N$ in number/month and the calibration of the fits and the data presented involve all available data. The dashed lines show the best linear-log fits, where the black line represents the combined fit for the Atlatnic and the North-West Pacific.

as input for Eq. (4), the predictions provide a reasonable description of the long-term evolution in the number of TCs (right panel), with the exception before 1900. The simple statistical model based on this expression (Eq. 4) captures the rapid increase in the number of TCs for the 2005 season, as well as weak trends in the past.

A similar analysis with temperature-weighted area $\left(A_{T}(t)=\sum_{i j} w_{j} \gamma_{i j}(t) \times \mathcal{H}\left(T_{i j}(t)-T_{\text {crit }}\right)\right)$, where each gridbox was scaled by $T_{i j}(t)$ (in ${ }^{\circ} \mathrm{C}$ ) gave similar results, although improved correlations for the North-West Pacific (for $T_{\text {crit }}=26.0^{\circ} \mathrm{C} r=0.29$ with a $p$-value $=0.07$ over the independent years 1950-1987). Since the temperature in the grid-box where $T_{i j}(t) \geq T_{\text {crit }}$ are of similar magnitude $\left(26^{\circ} \mathrm{C}<\gamma_{i j}(t)=T_{i j}(t)<35^{\circ} \mathrm{C}\right)$, the effect of the scaling only modifies the area-based analysis. When the peak over threshold $\left(\gamma_{i j}(t)=T_{i j}(t)-T_{\text {crit }}\right)$ were used as scaling, however, then the results suggested a weak relationship.

\section{Discussion}

This study does not attempt to provide a rigorous physical basis for the non-linear SST-dependent behaviour. Instead, empirical evidence is analysed in a new way to shed light on the relationship between the number of TCs and the area of SST $>26.5^{\circ} \mathrm{C}$. The analysis suggest that it is the area of the warm region, rather than the excessive temperatures above the threshold values, that is important for the cyclone number. 
Obs. \& predicted TC frequency/season

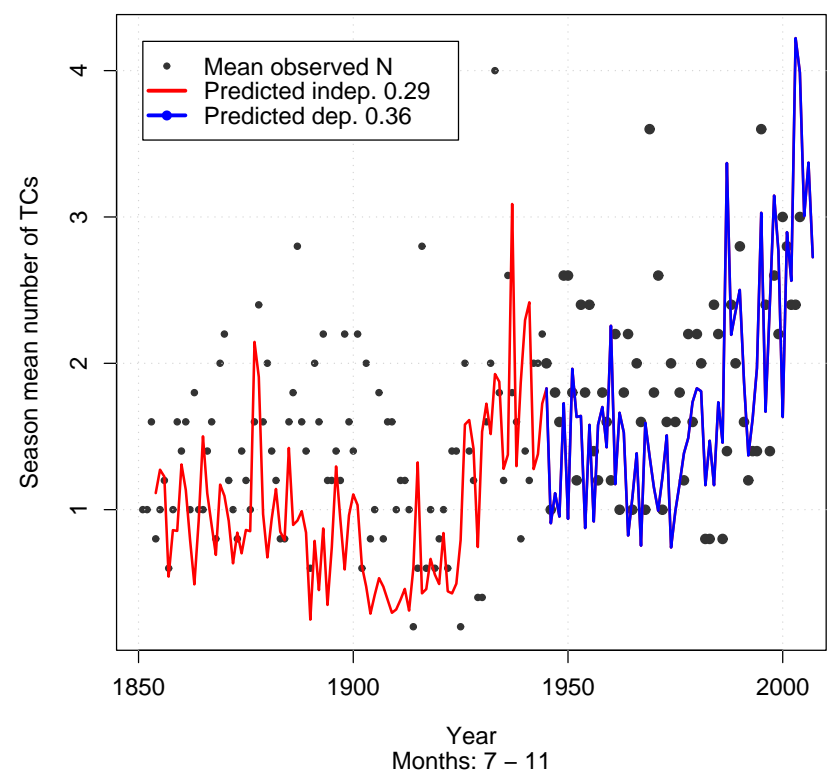

Fig. 8. Observed and predicted $N$ for the Atlantic, based on Eq. (4). Correlation coefficients are provided in the legend $\left(T_{\text {crit }}=26.5^{\circ} \mathrm{C}\right)$.

It is possible that the relationship found here may be more complicated than it first appears, as other conditions also undergoing similar annual cycles may introduce misleading biases in the end results. On the other hand, factors other than SST that may affect TCs are most likely not independent of the SSTs (shear, humidity, CAPE, El Niño, etc.), so that the area of the warm sea may also be regarded as proxy for all these aspects (Chauvin et al., 2006). Klotzbach and Gray (2008) argued, however, that the statistical description is improved by combining sea-level pressure with SST in the statistical analysis of TCs.

One interesting aspect is the tendency of similar linear log$\log$ relationship between $N$ and $A$ in the Pacific Ocean and the Atlantic, but a different character in the Indian Ocean basin. Holland (1997) suggested that different mechanisms may be operating in different ocean basins, and Yoshimura et al. (2006) found from model studies that there may be different response in the TC statistics to a global warming. For instance, the El Niño Southern Oscillation (ENSO) has different effects on tropical cyclones in the North-West Pacific and the North Atlantic.

The different oceans are characterised with different dynamics (ocean currents), geometry, and overlying atmospheric circulation (e.g. monsoon systems, easterly waves), all of which may play a role in terms of cyclogenesis. Further work is required to discriminate the role of atmospheric processes from the effect of $A$. So far, only similar phase lag in the annual cycle and independent year-to-year correlation analysis suggest a connection.
The statistical models trained on seasonally varying values (Eq. 4) did not yield skillful predictions for year-to-year variations in $N$ over the North Indian Ocean. The reason for the negative correlation between predicted and observed year-toyear variations in $N_{\text {Ind }}$ may be associated with the different magnitudes in the double-peak structure, weak statistical relation, and the large scatter in seen in Fig. 5. Furthermore, the phase match between $N$ and $A$ was not perfect for the Indian Ocean.

The physical explanation for this may be the small annual variations in $A$, constraints imposed by the northern boundary, or that the variations in SST above the threshold value mainly take place southward of the Tropic of Cancer. The northern boundary of the Indian Ocean is close to the Tropic of Cancer (Fig. 1), and southward of this latitude the solar inclination angle reaches a maximum twice a year. Hence much of the variation in the North Indian Ocean warm sea region may take place southward of $23.5^{\circ} \mathrm{N}$, where the solar inclination is expected to exhibit a double peak. Furthermore, the southwest Asian Monsoon has a similar twice-a-year wind reversal over the Indian Ocean, and the Indian Ocean winds influence the seasonal evolution of surface fluxes, convection, and ultimately affect the SSTs. There is a close coupling between the tropical ocean and the atmosphere.

The value for $N$ over the Indian Ocean was in general above the predictions on $A$ in Fig. 5, which is also consistent with the explanation that some TCs may originate in the Pacific basin but end up in the Indian Ocean.

It is also possible that the low year-to-year correlation and low statistical significance for the Indian Ocean and the North-West Pacific may be a result of lower data quality in these basins (Landsea et al., 2006), shorter series, or due to stronger influence from other factors such as atmospheric conditions not directly related to the warm pool area (Chan, 2006; Klotzbach, 2006). Both the Indian Ocean and North-West Pacific records are short compared to the Atlantic record, and the annual cycles are hence more strongly affected by noise.

There are further limitations to the data on which this analysis rests, as the TC series should not be considered homogeneous. The Atlantic TC data after 1944 is thought to have higher quality than the earlier observations (Goldenberg et al., 2001), however, the hurricane record is most reliable after 1970 (Trenberth et al., 2007).

The ability to detect TCs in the open Atlantic has increased substantially over time as aircraft reconnaisance and (in the 1970s) satellite monitoring have become available. These improvements in detection tools may have led to enhanced probability of detection of weak and remote TCs over time, although estimated maximum potential intensities of tropical cyclones appear to show some agreement with the observations (Henderson-Sellers et al., 1998).

Yet others argue that the best data quality is confined to more recent measurements, as Klotzbach (2006) argued 

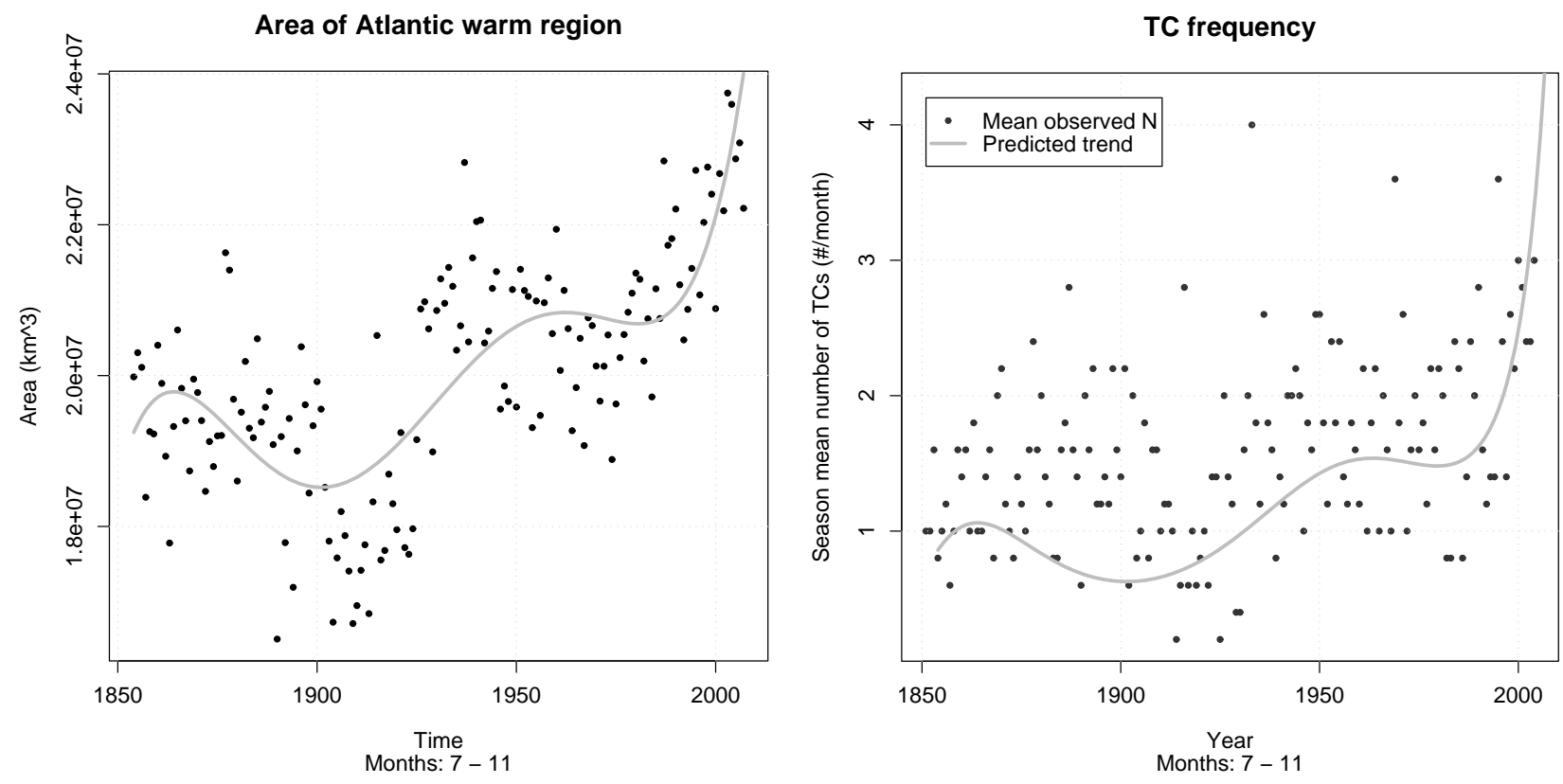

Fig. 9. (a) The area of the Atlantic warm region $A$ and (b) a reconstruction of the trend in $N$ for historic Atlantic TCs based on trend in $N_{\text {Atl }} \propto A_{\text {Atl }}^{6.64}$. Here a polynomial trend model was used because of the non-linear relationship between $A_{\text {Atl }}$ and $N_{\text {Atl }}$. Here $A$ is in units of $\mathrm{km}^{2}$ and $N$ in number/month $\left(T_{\text {crit }}=26.5^{\circ} \mathrm{C}\right)$.

that an improved Dvorak technique due to the introduction of IR measurements has enhanced the quality of the maximum wind estimates since 1984 . Thus, there may be inhomogeneities introduced by problems in measuring and estimating the hurricane intensities due to satellite improvements (Landsea et al., 2006), but a comparison with older independent data (Fig. 4) suggests that analysis presented here is not sensitive to such inhomogeneities.

Using the seasonal variations in $A$ and $N$ defined over the 1944-2004 interval will to some extent also alleviate problems associated with inhomogeneities in the TC record. The fact that the correlation analysis between predictions based on Eq. 4 and actual observations yielded results significant at the $1 \%$-level for independent (older) data, provides strong support for the statistical model established here for the Atlantic/Carribean basin. Evaluation against independent data by dividing the data in to two periods, is a more stringent test than simply using cross-validation (Wilks, 1995). Furthermore, months with low $N(y<-3)$ were excluded from the model training, but also these are approximately in line with the model predictions.

The warm area cannot account for all the variability and other factors, such as atmospheric conditions, also affect the number of TCs. An intriguing question is whether the annual variation of such factors are independent or affected by the warm area. Chauvin et al. (2006) found that the SSTs had a significant effect on the TC statistics, but was not the only factor. Their results suggested that the spatial SST structure was important as well as the magnitude.
Increases in the convective available potential energy (CAPE) are associated with increased near-surface temperature (Gettelman et al., 2002), suggesting that an increased warm area may enhance convection over a greater region and hence cause a more widespread vertical equalisation of horizontal momentum, and thus act to reduce the vertical shear. Hence, the role TCs play in the vertical redistribution of momentum and their effect on the ambient atmosphere may enhance the conditions of TC formation and growth. It is therefore plausible that the TCs are organised in time clusters, where the presence of one TC creates conditions that may favour the genesis of subsequent TCs, given sufficiently large area over which they can form. It is also plausible that a vertical re-distribution of heat and moisture, as a result of TC activity may, on the other hand, inhibit further TCs, if TCs equalise the vertical distribution of heat through some kind of "discharge mechanism".

Another speculation is whether time clustering of TCs may be associated with a modulation of TC occurrence by the Madden-Julian Oscillation (MJO), or conversely that the MJO is affected by the TCs.

Atlantic TCs are often triggered by $2000-3000 \mathrm{~km}$ long African easterly waves (AEWs) emanating from the African continent, associated with strong contrasts in temperature, moisture and wind flow across West Africa (Chronis et al., 2007). There tends to be 30-60 AEW episodes each summer. Thus, the number of AEWs are likely to constrain $N_{\text {Atl }}$.

Different trigger mechanisms may be present for different oceans, and AEW are limited to the Atlantic basin. Westerly wind bursts in the Pacific, and other situations where the 
convection starts to achieve a certain circular structure may spawn cyclones. Furthermore, the geography will provide an upper bound for the TC numbers (especially for the Northern Indian Ocean).

For a stochastic and static process, the number of events $(k)$ is expected to be distributed according to the Poisson distribution: $\operatorname{Pr}(X=k \mid A)=\frac{\mu^{k} e^{-\mu}}{k !}$. The question of how to regard $\mu$ in the case of TCs, as an average over time $\mu=\bar{\mu}$ or a variable $\mu=\mu(t)$ conditioned by changing external conditions, has a bearing on how $N$ should be modelled statistically. If $\mu$ varies with $A$, e.g. from season to season, one cannot expect the distribution for all historical TCs to follow a Poisson distribution if all events are put into one single batch.

Finally, a non-linear relationship between $A$ and $N$ may explain why linear trends in the TC frequency has not been detected in the past: There is a substantial response in $N$ only when $A$ reaches a certain size.

The non-linear relationship implies one caveat: taking the mean $A$ over a season will not provide an exact estimate of $N$ over the same season for a non-linear relationship $\left(N(t)=c \int_{t} A^{x}(t) d t \neq c \bar{A}^{x} t\right)$, especially for high values of $A$. Thus, these results should only be regarded as approximate.

These results may seem to disagree with most GCM-based studies (Meehls et al., 2007; Chauvin et al., 2006; Yoshimura et al., 2006), but this analysis only took into account variations in the warm area, and changes in the atmospheric environments do also play a role. Competing effects, such as greater hydrostatic stability, and wind shear may counter-act the effect of higher SSTs. However, these findings seem to be in line with Lau et al. (2008).

High-resolution model studies also indicate reduction in the global number of TC, but the models must demonstrate that they reproduce both the past trends in the TC statistics as well as the seasonal relationships presented here, in order to prove that they give a representative picture of TCs. At the present, the GCMs do not reproduce the observed SSTwind relationships (Yoshimura et al., 2006), and may be too sensitive to the cloud parameterisation schemes.

Vecchi et al. (2008) argue that the effect of a global warming - both for the past and in the future - on the tropical Pacific is highly uncertain, as some studies suggest a shift towards a state more like La Niña (mainly oceanic processes) while others (atmospheric processes) point to a more El Niño like state. Furthermore, depending on whether one looks at the HadISST or the NOAA extended reconstruction of SST, one finds that the shift in the past has been towards a more La Niña or El Niño like state, respectively. Thus, the uncertainty in the long-term changes will likely have consequences for the evolution in ENSO, and hence the TC statistics in some ocean basins. It is at present not possible to resolve the issues regarding the homogeneity in either the TC or SST record. Nevertheless, the statistical patterns identified in this analysis are interesting.
This study involved no physical basis as such, as it merely presented empirical data in a new fashion to outline some intriguing features. The results derived here falsify two hypotheses: (i) that TCs are random and (ii) that $N$ is insensitive to $A$ as claimed by Henderson-Sellers et al. (1998).

\section{Conclusions}

Here empirical data has been organised and presented in a new fashion. The correlation analyses between predictions and year-to-year variations in the seasonal mean TC-number suggest that a simple statistical model, based on the warm sea area, captures a part of the variations over the North Atlantic and Caribbean basins, to a lesser degree over the North-West Pacific, but not over the North Indian Ocean. For the Atlantic basin, these results are inconsistent with TCs being purely stochastic processes taking place over warm ocean regions, and provide strong evidence for a real connection between $N$ and $A$. Thus, these conclusions are inconsistent with the claim that the region of cyclogenesis will not expand with the $26.5^{\circ} \mathrm{C}$ isotherm. These results furthermore suggest that there may be a non-linear relationship between the area of high SST and the number of TCs in some ocean basins, which can explain why there in the past has not yet been a clear linear upward trend in the number of TCs associated with the general warming. It also explains the recent upturn in the number of TCs. One important caveat of this study is that it is based purely on a limited selection of empirical data.

Acknowledgements. The work has been supported by "Norsk Meteorolog Forening" and to some extent by the Norwegian Meteorological Institute, as much of this work was done during travels to Utrech (EMS), Berlin, and Helsinki. Inputs from E. A. Smith, NASA/GSFC and A. V. Mehta through the review process and $\varnothing$. Nordli have been valuable.

Edited by: A. Mugnai

Reviewed by: E. A. Smith

\section{References}

Benestad, R. E.: What can present climate models tell us about climate change? Climatic Change, 59, 311-332, 2003.

Benestad, R. E., 2006: An explanation for the lack of trend in the hurricane frequency, arXiv: physics/0603195., http://arxiv.org/ abs/physics/0603195, March 2006.

Bengtsson, L., Hodges, K. I., and Roeckner, E., Storm Tracks and Climate Change, J. Climate, 19, 3518-3542, 2006.

Chan, J.: Comments on "Changes in Tropical Cyclone Number, Duration, and Intensity in a Warming Environment", Science, 311, 1713b, doi:10.1126/science.1121522, 2006.

Chauvin, F., Royer, J.-F., and Déque, M.: Response of hurricanetype vortices to global warming as simulated by ARPEGEClimate at high resolution, Clim. Dynam., 27, 377-399, 2006. 
Chronis, T., Williams, E., Anagnostou, E., and Petersen, W.: African Lightning: Indicator of Tropical Atlantic Cyclone formation, Eos, 88, 397-398, doi:10.1029/2007EO400001, 2007.

Chu, J.-H., Sampson, C. R., Levin, A. S., and Fukada, E.: The Joint Typhoon Warning Center tropical cyclone best tracks 19452000 report, Joint Typhoon Warning Cent., Pearl Harbor, Hawaii, 2002.

Emanuel, K.: Increasing destructiveness of tropical cyclones over the past 30 years, Nature, 436, 686-688, 2005.

Gettelman, A., Seidel, D. J., Wheeler, M. C., and Ross, R. J.: Multidecadal trends in tropical convective available potential energy, J. Geophys. Res., 107(D21), 4606, doi:10.1029/2001JD001082, 2002.

Goldenberg, S. B., Landsea, C. W., Mestas-Nunez, A. M., and Gray, W. M.: The recent Increase in Atlantic Hurricane Activity: Causes and Implications, Science, 293, 474-479, 2001.

Gray, W. M.: A global view of the origin of tropical disturbances and storms, Mon. Weather Rev., 96, 669-700, 1968.

Henderson-Sellers, A., Zhang, H., Berz, G., Emanuel, K., Gray, W., Landsea, C., Holland, G., Lighthill, J., Shieh, S.-L., Webster, P., and McGuffie, K.: Tropical Cyclones and Global Climate Change: A Post-IPCC Assessment, B. Am. Meteorol. Soc., 79, 20-38, 1998.

Holland, G. J.: The maximum potential intensity of tropical cyclones, J. Atmos. Sci., 54, 2519-2541, 1997.

Holland, G. J.: Misuse of Landfall as a Proxy for Atlantic Tropical Cyclone Activity, Eos, 88, 349-356, 2007.

Hoyos, C. D., Agudelo, P. A., Webster, P. J., and Curry, J. A.: Deconvolution of the Factors Contributing to the Increase in Global Hurricane Intensity, Science, 312, 94-97, 2006.

Jung, T., Gulev, S. K., Rudeva, I., and Soloviov, V.: Sensitivity of extratropical cyclone characteristics to horizontal resolution in the ECMWF model, Research Dept., Technical Memorandum 485, ECMWF, 2006.

Klotzbach, P. J.: Trends in global tropical cyclone activity over the past twenty years (1986-2005), Geophys. Res. Lett., 33, L10805, doi:10.1029/2006GL025881, 2006.

Klotzbach, P. J. and Gray, W. M.: Multidecadal Variability in North Atlantic Tropical Cyclone Activity, J. Climate, 21, 3929-3935, doi:10.1175/2008JCLI2162.1, 2008.

Knutson, T. R. and Tuleya, R. E.: Impact of $\mathrm{CO}_{2}$-Induced Warming on Simulated Hurricane Intensity and Precipitation: Sensitivity to the Choice of Climate Model and Convective Parameterization, J. Climate, 17, 3477-3495, 2004.

Knutson, T. R. and Tuleya, R. E.: Reply, J. Climate, 18, 5183-5187, 2005.

Landsea, C. W., Harper, B. A., Hoarau, K., and Knaff, J. A.: Can we detect trends in extreme tropical cyclones?, Science, 313, 452454, 2006.

Landsea, C. W.: Counting Atlantic Tropical Cyclones Back to 1900, Eos, 88, 197-202, 2007.

Lau, K. M., Zhou, Y. P., and Wu, H. T.: Have tropical cyclones been feeding more extreme rainfall?, J. Geophys. Res., 113, D23113, doi:10.1029/2008JD009963, 2008.

Lau, W. K. M. and Kim, K.-M.: How Nature Foiled the 2006 Hurricane Forecasts, Eos, 88(9), 105-107, 2007.
Mann, M. E., Emanuel, K. A., Holland, G. J., and Webster, P. J.: Atlantic Tropical Cyclones Revisited, Eos, 88(36), 49 pp., 2007.

Meehls, G. A., Stocker, T. F., Idlingstein, W. D., Gaye, A. T., Gregory, J. M., Kitoh, A., Knutti, R., Murphy, J. M., Noda, A., Raper, S. C. B., Watterson, I. G., Weaver, A. J., and Zhao, Z.-C.: Climate Change: The Physical Science Basis, United Kingdom and New York, NY, USA, Cambridge University Press, Chap. Global Climate Projections, 2007.

Michaels, P. J., Knappenberger, P. C., and Davis, R. E.: Sea-surface temperatures and tropical cyclones in the Atlantic basin, Geophys. Res. Lett., 33, L09708, doi:10.1029/2006GL025757, 2006.

Pearce, R.: Comments on "Why must hurricanes have eyes?" revisited, Weather, 60(11), 329-330, 2005a.

Pearce, R.: Why must hurricanes have eyes? Weather, 60(1), 19-24, 2005b.

Randall, D. A., Wood, R. A., Bony, S., Colman, R., Fichefet, T., Fyfe, J., Kattsov, V., Pitman, A., Shukla, J., Srinivasan, J., Stouffer, R. J., Sumi, A., and Taylor, K. E.: Climate Change: The Physical Science Basis, Cambridge, UK: Cambridge University Press, Chap. Climate Models and Their Evaluation, 2007.

Scharroo, R., Smith, W. H., and Lillibridge, J. L.: Satellite Altimetry and the Intensification of Hurricane Katrina, Eos, 366 pp., 2005.

Scharroo, R., Smith, W. H. F., and Lillibridge, J. L.: Reply to Comment on "Satellite Altimetry and the Intensification of Hurricane Katrina”, Eos, 87(8), 89 pp., 2006.

Smith, R. K.: "Why must hurricanes have eyes?" - revisited, Weather, 60(11), 326-328, 2005.

Sun, D., Gautam, R., Cervone, G., Boybeyi, Z., and Kafatos, M.: Comment on "Satellite Altimetry and the Intensification of Hurricane Katrina”, Eos, 87(8), 89 pp., 2006.

Trenberth, K.: Uncertainty in Hurricanes and Global Warming, Science, 308, 1753-1754, 2005.

Trenberth, K. E., Jones, P. D., Ambenje, P., Bojariu, R., Easterling, D., Klein Tank, A., Parker, D., Rahimzadeh, F., Renwick, J. A., Rusticucci, M., Soden, B., and Zhai, P.: Climate Change: The Physical Science Basis, Cambridge, UK, Cambridge University Press, Chap. Observations: Surface and Atmospheric Climate Change, 2007.

Vecchi, G. A., Clement, A., and Soden, B.: Examining the Tropical Pacific's Response to Global Warming, Eos, 89(9), 81 pp., 2008.

Vitard, F., Stockdale, T., and Ferranti, L.: Seasonal forecasting of tropical storm frequency, ECMWF Newsletter, 16-22, 2007.

Webster, P. J., Holland, G. J., Curry, J. A., and Chang, H.-R.: Changes in Tropical Cyclone Number, Duration, and Intensity in a Warming Environment, Science, 309, 1844-1846, 2005.

Wilks, D. S.: Statistical Methods in the Atmospheric Sciences, Orlando, Florida, USA, Academic Press, 1995.

Wu, M-.C., Yeung, H., and Chang, W-.L.: Trends in Western North Pacific Tropical Cyclone Intensity, Eos, 87(48), 537 pp., 2006.

Yoshimura, J., Masato, S., and Noda, A.: Influence of Greenhouse Warming on Tropical Cyclone Frequency, J. Meteorol. Soc. Jpn., 84(2), 405-428, 2006. 